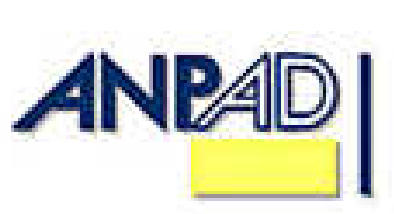

Disponível em

http://www.anpad.org.br/rac

RAC, Curitiba, v. 14, n. 1, art. 3, pp. 40-60, Jan./Fev. 2010

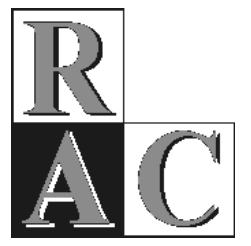

\title{
Os Conflitos entre a Prática Gerencial e as Relações em Família: uma Abordagem Complexa e Multidimensional
}

\section{Conflicts between Management Practice and Family Relations: a Complex and Multidimensional Approach}

\author{
Anielson Barbosa da Silva * \\ Doutor em Engenharia de Produção pela UFSC. \\ Professor do PPGA/UFPB, João Pessoa/PB, Brasil. \\ Carlos Ricardo Rossetto \\ Doutor em Engenharia de Produção pela UFSC. \\ Professor do PPGAT/UNIVALI, Biguaçu/SC, Brasil.
}

* Endereço: Anielson Barbosa da Silva Universidade Federal da Paraíba, Campus Universitário, João Pessoa/PB, 58059-900. E-mail: anielson@uol.com.br

Copyright @ 2010 RAC. Todos os direitos, inclusive de tradução, são reservados. É permitido citar parte de artigos sem autorização prévia desde que seja identificada a fonte. 


\title{
RESUMO
}

$\mathrm{O}$ artigo tem como objetivo compreender os significados da vivência de conflitos entre a prática gerencial e as relações em família. O estudo foi embasado epistemologicamente nos pressupostos do paradigma interpretativo, utilizou uma abordagem qualitativa e foi realizado com gerentes que atuam no Banco do Brasil. O conflito entre a prática gerencial e as relações em família está vinculado ao tempo dedicado ao exercício de papéis no trabalho e na família, à incompatibilidade de interesses e às divergências de percepção e de visão entre os agentes envolvidos. A pesquisa revelou a existência de fatores que geram conflito na prática gerencial e nas relações em família. A percepção dos gerentes é que os conflitos nas relações em família os afetaram emocionalmente e isso interfere no desempenho da prática gerencial. Abordar o tema numa perspectiva complexa e multidimensional é uma forma de reconhecer a existência de conexões espaciais, temporais e comportamentais e essa constatação pode auxiliar a compreender a experiência vivida de gerentes de forma singular e multifacetada. Estudos adicionais devem considerar os vínculos entre o gênero, a personalidade, o contexto, o tipo de trabalho e o estágio na carreira. Espera-se que o tema amplie o foco de análise do conflito e auxilie na compreensão da teoria e da prática organizacional.

Palavras-chave: conflito; gerente; relação trabalho e família.

\begin{abstract}
This article seeks to understand the meanings of conflict experience between management practice and family relations. The study, based epistemologically on the premises of the interpretative paradigm, used a qualitative approach and was conducted with managers who work at the Brazil Bank. The conflict between the management practice and the relations in the family is related to the time devoted to exercising the roles of work and family, the incompatibility of interests and differing perceptions on the part of the agents involved. The research revealed the existence of factors that provoke conflict in management practice and in family relationships. The managers' perception is that the conflicts in family relations affected them emotionally and interfere in their professional performance. Addressing the issue in a complex and multidimensional perspective is a way to acknowledge the existence of spatial, temporal and behavioral connections, and this finding may help to understand the experience of the managers in a unique and multifaceted way. Additional studies should consider the links between gender, personality, context, nature of work and career stage. It is hoped that the theme will broaden the analysis focus of conflict and support in the understanding of organizational theory and practice.
\end{abstract}

Key words: conflict; manager; work and family relations. 


\section{INTRODUÇÃO}

O trabalho e a vida em família de gerentes sofreram e ainda sofrem várias transformações. O gerente ampliou o escopo de sua atividade, ao incorporar à dimensão técnica uma perspectiva mais estratégica, complexa e multifacetada. Do inicio do século XX até a década de 1970, o trabalho nas organizações era caracterizado por modelos tayloristas e fordistas (Antunes, 2000; Harvey, 2000; Heloani, 1994). Com a introdução da acumulação flexível, apoiada na flexibilidade dos processos de trabalho, houve um confronto com a rigidez do fordismo e emergiram novas relações de trabalho (Harvey, 2000).

Alguns autores realizaram estudos no campo da gerência com o objetivo de delimitar o escopo da atividade gerencial (Barnard, 1971; Escrivão, 1995; Fayol, 1994; Kotter, 1982; Mintzberg, 1973, 1990; Tonelli \& Alcadipani, 2003), que engloba um conjunto de papéis (Mintzberg, 1990), funções (Fayol, 1994; P. R. Motta, 1991) ou competências (Le Boterf, 2003; Quinn, Fareman, Thompson, \& McGrath, 2003), que se tornaram mais complexas ao longo do tempo (Stewart \& Fondas, 1992). As mudanças no ambiente empresarial afetaram a prática gerencial e influenciaram as relações dos gerentes fora do trabalho, uma vez que a competição por um espaço no mercado demanda a necessidade de grande investimento pessoal (energia e tempo) para o desenvolvimento profissional.

Por outro lado, a família também passou por transformações nas últimas décadas, decorrentes de fatores econômicos, sociais, políticos e culturais, promovendo ajustes nos estilos de vida e incorporando novos valores e atitudes. Esse processo de transformação na estrutura familiar também demanda novas configurações e relações familiares, as quais revelam uma mudança na compreensão da família, que deixa de ser concebida como núcleo econômico e reprodutivo e passa a ser percebida à luz de uma visão socioafetiva (Farias, 2004).

A família exerce papel central na trajetória de vida das pessoas e na construção de uma identidade social. Ela é a mola propulsora para a dignidade das pessoas, o ambiente propício para o desenvolvimento da personalidade humana (Farias, 2004), um espaço de interações afetivas (Farias, 2004; Lôbo, 2004; Romagnoli, 1996), de aprendizado e crescimento (Romagnoli, 1996), que é movido pelo afeto (Farias, 2004), relacionamento (Desiderio, 1983; Romagnoli, 1996), convivência e respeito mútuo (Desiderio, 1983) e busca de realização pessoal (Farias, 2004).

Para Parcel (1999), as questões relacionadas à interseção entre o trabalho e a família se tornaram o centro das atenções de pesquisadores, formuladores de políticas e cidadãos, pois no coração dessa junção crítica está a alocação do tempo para cada instituição e as estratégias que as famílias empregam para cumprirem suas obrigações no trabalho e em casa.

Nas últimas três décadas, houve um crescimento na quantidade de pesquisas com o objetivo de compreender as relações entre a vida no trabalho e a vida pessoal (Carponi, 1997; Debord, Canu, \& Kerpelman, 2000; Haddock, Zimmerman, Ziemba, \& Curent, 2001; Kerslake, 2002; Kiecolt, 2003; Kossek, Noé, \& Demarr, 1999; Lambert, 1990; Pittman, 1994; Quental \& Wetzel, 2002). Esses trabalhos ajudam a compreender a natureza do relacionamento entre os papéis vividos no trabalho e na família e o conflito nesta relação. Sennet (2000) coloca que a flexibilidade e os comportamentos associados à visão de curto prazo são geradores de conflitos entre o trabalho e a família.

Para Janasz e Behson (2007), os conflitos na relação trabalho e família estão associados a características situacionais (conflito de papéis) e demográficas (horas trabalhadas, número de filhos), que podem resultar em aumento de turnover, absenteísmo, estresse, burnout, redução nos níveis de satisfação e de comprometimento organizacional e insatisfação na vida conjugal (Wilson, PolzerDebruyne, Chen, \& Fernandes, 2007). A teoria dos papéis, por exemplo, sugere que o conflito ocorre, quando as pessoas se engajam em múltiplos papéis que são incompatíveis (Katz \& Kahn, 1987).

Wilson et al. (2007) destacam a existência de dois direcionamentos distintos, ligados de forma recíproca, envolvendo o conflito de papéis na relação trabalho e família. O primeiro deles é associado a aspectos estruturais ou de desenvolvimento da família. Os conflitos surgem na família, têm impacto 
no comportamento e interferem nas responsabilidades relacionadas ao trabalho. O segundo indica que a dedicação aos papéis desenvolvidos no trabalho pode dificultar os papéis ligados à família. As demandas do tempo para o trabalho interferem nas responsabilidades ligadas à família e geram conflito. Esses dois direcionamentos indicam que o conflito pode ter a sua origem na família e interferir no trabalho, ou vice-versa, o que caracteriza a sua bidirecionalidade.

Este artigo teve como referência esta discussão e objetivou compreender os significados da vivência de conflitos entre a prática gerencial e as relações em família, segundo a percepção de gerentes que atuam em uma agência do Banco do Brasil.

Vale ressaltar que o estudo realizado aborda o conflito a partir de uma perspectiva complexa (Morin \& Lemoigne, 2000; Silva \& Rebelo, 2003) e multidimensional (Chanlat, 1992), uma vez que as relações entre o trabalho e a família ocorrem de várias maneiras e em diferentes níveis, se inserem em sistema complexo (a vida) e essa complexidade permeia a natureza humana e a sua relação com o mundo. Vislumbrar o conflito a partir de perspectiva complexa e multidimensional é a forma de resgatar o espaço do ser humano na dimensão trabalho e na dimensão família, de maneira integrada e não fragmentada. A fundamentação teórica da pesquisa a respeito do conflito na relação trabalho e família é apresentada a seguir.

\section{FUNDAMENTAÇÃO TEÓRICA}

O conflito pode ocorrer em vários níveis. No nível individual ou em grupo surge "quando uma parte (indivíduo ou grupo) percebe a outra como obstáculo à satisfação de suas preocupações, o que provocará um sentimento de frustração que poderá levar, posteriormente, a reagir em face da outra parte" (Rondeau, 1996, pp. 206-207). Apesar de o conceito ser limitado, o autor aponta algumas características que são geralmente associadas à existência de conflitos: a interdependência das partes; a incompatibilidade percebida por uma delas; e a interação social onde se exprimem os conflitos.

Segundo Robbins (2002), o conflito é "um processo que tem início quando uma das partes percebe que a outra parte afeta, ou pode afetar, negativamente, alguma coisa que a primeira considera importante" (p. 373). Já Follet (1997) associa o conflito às diferenças e não podemos evitá-lo, mas utilizá-lo. "Em vez de condená-lo, deveríamos fazer com que trabalhasse a nosso favor" (p. 71). Outra concepção a respeito do conflito envolve os papéis sociais. Katz e Kahn (1987) abordam o conflito e o definem como "a ocorrência simultânea de dois (ou mais) papéis, de tal modo que o desempenho de um tornaria mais difícil o desempenho do outro" (p. 205). F. C. P Motta e Vasconcelos (2002) destacam que a incompatibilidade entre papéis cria expectativas contraditórias que provocam pressões opostas e podem afetar a experiência emocional das pessoas, intensificando os conflitos internos, aumentando a tensão no trabalho e também contribuindo, por exemplo, para a redução no desempenho e na satisfação com o trabalho (Janasz \& Behson, 2007; Wilson et al., 2007).

O conflito sempre estará presente nas organizações, manifestando-se no nível pessoal, interpessoal ou entre grupos e organizações (Morgan, 1996). Para o autor, o conflito...

pode ser construído dentro das estruturas organizacionais, nos papéis, nas atitudes e nos estereótipos, ou surgir em função de recursos escassos. Pode ser explícito ou implícito. Qualquer que seja a forma que assuma, a sua origem reside em algum tipo de divergência de interesses percebidos ou reais (p. 160).

P. R. Motta (1991) aponta a existência de várias abordagens sobre os conflitos e as enquadra dentro de três correntes: a dos conflitos de interesses, a dos conflitos de papéis e a dos conflitos de personalidade e de percepções individuais e de pequenos grupos. Rondeau (1996) reconhece a existência de dois modelos que servem para descrever o fenômeno. Um desses modelos é o estrutural, que propõe quadros de referência para compreender as condições gerais em que se 
desenvolve um conflito, para melhor apreender os fatores suscetíveis de influenciar o comportamento das partes envolvidas. O outro modelo é o processual, que procura descrever a dinâmica de uma situação de conflito, e busca ilustrar as transformações vividas pelas partes, quando ocorre um episódio conflitual.

Inspirado nesses dois modelos, Rondeau (1996) propõe uma análise do conflito a partir de três perspectivas: estrutural, dinâmica e diacrônica. Robbins (2002), por sua vez, classifica o conflito como funcional ou disfuncional. O funcional considera o conflito como construtivo, apoiado nos objetivos do grupo e objetiva melhorar o seu desempenho. Já o disfuncional aborda que existem maneiras destrutivas de conflito que atrapalham o desempenho do grupo.

Uma análise do conflito à luz das várias definições, perspectivas, abordagens e classificação para o constructo indica a sua natureza multifacetada e bidirecional, o que reforça a emergência de uma perspectiva mais complexa para ampliar o escopo de análise, percebendo o conflito não apenas de forma negativa, mas como espaço para reflexão e mudança na perspectiva de significado da vida das pessoas dentro e fora da organização.

$\mathrm{Na}$ relação trabalho e família, vários autores consideram o conflito como de papéis, em que as demandas de um domínio (trabalho ou família) são mutuamente incompatíveis com as demandas de outro domínio (família ou trabalho) (Carlson \& Kacmar, 2000; Greenhaus \& Beutell, 1985; Wilson et al., 2007).

As demandas conflitantes do trabalho e da vida pessoal sempre estiveram presentes no cotidiano das pessoas (Quental \& Wetzel, 2002). No caso dos gerentes, esse conflito surge no momento em que o exercício do papel da gerência entra em choque com os papéis que eles exercem na família ou viceversa. Essa incompatibilidade acaba provocando problemas. Greenhaus e Beutell (1985) argumentam que o conflito entre trabalho e família existe quando o tempo dedicado às necessidades de um papel torna difícil satisfazer as necessidades do outro; quando a tensão da participação em um papel torna difícil a satisfação das necessidades do outro; e quando os comportamentos específicos requeridos por um papel dificultam a satisfação das necessidades do outro.

Quando os conflitos entre esses dois domínios ocorrem, surgem conseqüências adversas para os indivíduos e para as organizações. As pessoas que enfrentam os conflitos entre o trabalho e a família podem ter aumento do risco de doenças, desempenho inadequado com um parceiro ou parente, redução da satisfação em relação à vida e desajuste no casamento (Fu \& Shaffer, 2001).

Com base em uma análise de vários estudos, Ahmad (2003) destaca que existe uma variedade de antecedentes (incluindo ambigüidade, conflitos de papéis, demandas de tempo e envolvimento com os domínios do trabalho e da família) que levam as pessoas a vivenciarem conflitos.

Marchese, Basshan e Ryan (2002) citam vários estudos do conflito na relação trabalho e família realizados no campo da Administração. Eles constataram que o conflito é um constructo bidirecional e ocorre de duas formas: a) o trabalho interferindo na vida em família (trabalho $\rightarrow$ conflito na família); e b) vida familiar interferindo nas responsabilidades no trabalho (família $\rightarrow$ conflito no trabalho).

Para pessoas que exercem cargos gerenciais, esses conflitos assumem papel relevante, pois como sua atuação é condição sine qua non para a transformação organizacional (Moscovici, 2000), a vivência de conflitos pode prejudicar o seu desempenho e também a qualidade de vida fora do trabalho (Evans, 1996). O trabalho e a família estão interconectados. Manter um relacionamento harmonioso entre essas duas dimensões beneficia as pessoas e as organizações (Fu \& Shaffer, 2001).

O artigo de Greenhaus e Beutell (1985) é um dos mais citados na literatura de conflito na relação trabalho e família. Os autores abordam as fontes de conflitos entre os papéis do trabalho e da família. Eles discutem a natureza desses conflitos, destacando os conflitos de papéis, os conflitos entre papéis e os conflitos entre o trabalho e a família. 
Vale lembrar que essa tipologia de conflitos não pode ser percebida de forma isolada. Carlson, Kacmar e Stepina (1995) argumentam que os estudos desses tipos de conflitos demonstram resultados divergentes e apontam a existência de outros fatores como necessários para explicar as fontes de conflitos entre trabalho e família de maneira mais completa. Um desses fatores é a identidade social.

A partir da análise de alguns estudos do conflito na relação trabalho e família, pôde-se constatar que os autores direcionaram seu foco de análise nos seguintes aspectos: determinantes do conflito (Fu \& Shaffer, 2001); conflitos de papéis (Valcour, 2002); principais fontes de conflito (Greenhaus \& Beutell, 1985); tipos de conflitos (Rizzo, House, \& Lirtman, 1970); modelos de conflito (Carlson \& Kacmar, 2000; Smyrnios et al., 2003); antecedentes que geram conflito (Ahmad, 2003); bidirecionalidade dos conflitos, ou seja, trabalho gerando conflito na família e família gerando conflito no trabalho e suas conseqüências (Marchese et al., 2002); relação entre tempo, identidade e suas incongruências na geração de conflitos (Carlson et al., 1995); e os significados derivados do conflito na vida no trabalho e fora dele, utilizando o tempo como uma metáfora para o balanço da relação (Thompson \& Bunderson, 2001).

$\mathrm{Na}$ próxima seção, será delimitado o caminho metodológico percorrido durante a realização do estudo, com o intuito de caracterizar o design da pesquisa, além de delimitar o processo de coleta dos relatos das experiências dos gerentes e as etapas da análise compreensiva e interpretativa dos dados ${ }^{(1)}$.

\section{CAMINHO MetOdológico}

O estudo realizado com gerentes foi embasado, epistemologicamente, nos pressupostos do paradigma interpretativo (Burel \& Morgan, 1979). Essa orientação paradigmática entende a sociedade de um ponto de vista do participante em ação em vez do observador (Morgan, 1980). A partir da delimitação da visão subjetiva da realidade, preconizada no paradigma interpretativo, a pesquisa utilizou uma abordagem qualitativa, que não é um conjunto específico de técnicas, mas abordagem para compreender fenômenos sociais (Morgan \& Smircich, 1980, p. 491).

$\mathrm{Na}$ pesquisa qualitativa, os pesquisadores estão interessados nos significados construídos pelos sujeitos a partir das experiências como foram vividas ou sentidas (Merriam, 1998). Dentre os vários métodos de pesquisa citados por Merriam (1998), optou-se por realizar um estudo qualitativo básico, mas também foram utilizados os pressupostos do método fenomenológico no processo de análise dos dados (Barrit, Beekman, Bleeker, \& Mulderij, 2000; Bicudo, 2000; Santos, 2004).

A pesquisa foi realizada com gerentes de uma instituição de Economia Mista do setor financeiro - o Banco do Brasil, especificamente em uma Agência localizada em uma capital do Sul do Brasil, responsável pelo atendimento dos entes públicos, aí incluídas as três esferas do Poder - Executivo, Legislativo e Judiciário.

A escolha dos gerentes e do tipo de atividade profissional ocorreu de forma intencional, caracterizando a amostra como não-probabilística (Merriam, 1998). Participaram da pesquisa seis gerentes. Todos são homens, casados, um deles tem um filho e cinco têm dois filhos. Os gerentes estão em uma faixa etária que varia de 41 a 51 anos e atuam no banco há mais de 22 anos. Quatro gerentes são graduados em Administração e dois em Ciências Contábeis. Um deles possui mestrado completo, dois estão cursando o mestrado, dois possuem pós-graduação lato sensu na área de Administração e um deles a graduação.

Para captar os relatos das experiências foi utilizado o método de entrevista fenomenológica em profundidade proposto por Seidman (1997). O método combinou a entrevista focada na experiência vivida e a entrevista em profundidade. Nessa abordagem, não existe um número de questões definidas a priori, pois o objetivo da entrevista foi levar os gerentes a descreverem as suas experiências, ressaltando a vivência de conflitos entre a prática gerencial e as relações em família. 
A entrevista em profundidade é um ciclo das experiências dos gerentes e foi dividida em três etapas (entrevistas): a primeira entrevista foi direcionada para a delimitação do contexto da experiência; a segunda procurou elucidar os detalhes das experiências inerentes aos conflitos entre a prática gerencial e as relações em família; e, a última teve como objetivo levar os gerentes a fazerem uma reflexão sobre os significados de suas experiências (Seidman, 1997). Esta etapa ocorreu após a transcrição das duas primeiras. Durante a sua realização, muitos gerentes iniciaram um processo de reflexão dos conflitos entre a prática gerencial e as relações em família.

Todas as entrevistas foram gravadas e transcritas literalmente, gerando protocolos que foram submetidos aos gerentes para que eles pudessem ler os relatos de suas experiências. Após os gerentes devolverem os protocolos teve início o processo de análise.

A análise compreensiva interpretativa dos dados delimita os passos para compreender o fenômeno. Esse processo de categorização e busca de significados envolve um movimento de ida e volta entre pedaços de dados concretos e conceitos abstratos, entre o raciocínio indutivo e dedutivo, entre a descrição e a interpretação (Merriam, 1998).

Durante a leitura e releitura dos protocolos das entrevistas ocorreu uma sensação de falta de direcionamento, mas os insights de como estabelecer uma estrutura para compreender os significados foram emergindo a partir da leitura dos livros de Manen (1990), Bicudo (2000) e Bicudo e Espósito (1994) e também do artigo de Barrit et al. (2000) e da tese de Doutorado de Santos (2004). A partir da leitura desses autores, que utilizaram a fenomenologia como método de pesquisa, foi desenvolvido um processo de análise dos dados, subdividido em sete etapas, que não são dissociadas, mas integradas, o que indica que o processo é cíclico. As etapas são: a) leitura e releitura de cada um dos protocolos das três entrevistas realizadas com os gerentes para a codificação dos discursos; b) transformação de protocolo de entrevistas em protocolo codificado com os relatos dos gerentes; c) leitura e releitura de todos os protocolos codificados para identificação de temas; d) agrupamento dos relatos dos gerentes por temas em quadros temáticos; e) preenchimento dos quadros temáticos; f) estruturação dos resultados em um texto sobre cada tema, tomando como base os quadros temáticos; e g) análise compreensiva interpretativa dos resultados.

Nos resultados apresentados a seguir não foram incluídos os discursos na linguagem do gerente, mas os significados decorrentes do processo de análise compreensiva interpretativa dos dados articulados com os pressupostos teóricos envolvendo o tema.

\section{Resultados DA PESQUISA}

Diante da análise compreensiva interpretativa realizada, constatamos o papel central das relações em família na vida dos gerentes, o que nos levou a fazer uma reflexão a respeito da representatividade da família na sociedade. Os significados atribuídos à família denotaram uma visão socioafetiva e também indicaram a sua importância no estabelecimento de padrões de referência culturais e sociais. Como a família foi considerada a base de tudo na vida dos gerentes, os pilares que dão sustentação a essas bases foram a afetividade e o relacionamento. O caráter dinâmico da família também ficou evidente, uma vez que os gerentes citaram os núcleos familiares (família de origem e família que construíram) como determinantes em seu desenvolvimento pessoal e profissional.

O diálogo, o apoio e a convivência se revelaram como bases das relações em família. Pela análise dos resultados, podemos constatar quanto essas bases auxiliaram os gerentes a evitar o surgimento de conflitos. A Tabela 1, a seguir, ilustra os significados atribuídos pelos gerentes à família e apresenta as bases das relações em família. 
Tabela 1

Espaço Social da Família: Significado e Bases das Relações em Família

\section{SIGNIFICADO DA FAMÍLIA}

- a família é a base de tudo.

- o sentido da existência.

- uma forma de realização pessoal.

- espaço mediado pela afetividade e pelo relacionamento.

- determinante na construção de valores.

- espaço onde se estabelecem os primeiros vínculos com a sociedade.

\section{BASES DA RELAÇÃO EM FAMÍLIA}

- diálogo (maneira de compartilhar experiências, de dar exemplos e de aumentar a cumplicidade. É mediado pelo respeito).

- apoio (dos pais, da esposa e de pessoas mais próximas na formação e desenvolvimento profissional, no atendimento das expectativas profissionais e na criação dos filhos).

- convivência (oportunidade de aprendizado; auxilia na construção de vínculos de afetividade e de conduta. $\mathrm{O}$ que propicia a convivência é a relação de troca, a capacidade de ouvir e a tomada de decisão compartilhada).

Vale considerar que as bases das relações em família podem configurar-se como desafio para muitos profissionais, pois demandam uma visão socioafetiva pautada no respeito, numa relação mais participativa, franca e aberta entre as partes envolvidas. O diálogo, o apoio e a convivência, apesar de terem sido considerados bases das relações em família, também foram fundamentais no exercício da prática gerencial. O diálogo com superiores, pares e subordinados pode auxiliar os gerentes a fomentar ações, visando criar um clima participativo e um ambiente propício para minimizar a incidência de conflitos que interfiram na relação entre o trabalho e a família. O apoio no contexto da prática gerencial pode ajudar os gerentes a alcançarem seus objetivos pessoais e profissionais. A convivência também é relevante, à medida que as relações interpessoais favorecem a implantação de um sistema de aprendizagem e a institucionalização de um relacionamento interpessoal centrado na afetividade, na participação e na capacidade de ouvir o outro.

A atividade gerencial é uma prática social e, como afirma Dewey (1979), "toda a prática social que seja vitalmente social ou vitalmente compartilhada é por sua natureza educativa" (p. 6). A adoção do termo prática gerencial também está associada à noção de saber prático (Reimbold \& Breillot, 1995) ou entendimento prático proposto por Zarifian (2001) em seu estudo das competências. Essas considerações denotam que a prática gerencial é resultante de um processo de aprendizagem, mediado pelo desenvolvimento de competências e também pela experiência. A prática gerencial é um conjunto de ações que envolvem atividades e papéis exercidos por gerentes no espaço social do trabalho. $\mathrm{O}$ papel e a atividade gerencial são temas centrais na administração (Maximiano, 2002).

No estudo realizado com os gerentes, o contexto da prática gerencial envolveu o ambiente externo e interno. Hill (1993) ressalta que "gerenciar o contexto significa identificar e estabelecer relações eficazes com as principais pessoas e grupos de quem suas equipes dependem" (p. 298). Para efeito deste estudo, o gerenciamento do contexto envolveu, além das considerações de Hill (1993), a introdução de uma filosofia de negócios que estivesse em consonância com a dinâmica competitiva do setor.

O Banco do Brasil passou por várias transformações, que tiveram como objetivo estabelecer um plano de ajustes a um novo cenário empresarial, visando torná-lo mais ágil e competitivo (Oliveira, 2001; Oliveira \& Moraes, 1999; Rocha \& Bastos, 1999; Salinas, Maçada, \& Ritter, 1998).

Isso se tornou evidente quando os gerentes ratificaram que a atividade bancária passou por transformações decorrentes do aumento de competitividade no setor. $\mathrm{O}$ aumento da concorrência e uma maior exigência dos consumidores foram apontados como determinantes para a introdução de uma nova filosofia de negócios no Banco do Brasil. 
No caso dos gerentes pesquisados, esse contexto favoreceu o surgimento de conflitos entre a prática gerencial e as relações em família, uma vez que passou a demandar mais tempo de dedicação dos gerentes para o trabalho em detrimento da família, além da necessidade de qualificação profissional visando, adequar-se às competências desejadas em cargo gerencial. $O$ contexto e os fatores determinantes delimitam atributos essenciais na prática gerencial e são ilustrados na Tabela 2.

Tabela 2

O Espaço Social da Prática Gerencial

\section{O CONTEXTO DA PRÁTICA GERENCIAL FATORES DETERMINANTES DA PRÁTICA GERENCIAL}

- comercialização de produtos e serviços bancários seguindo os parâmetros legais.

- dinâmico e competitivo

- foco no mercado sem descuidar dos processos internos

- motivador pela amplitude do mercado

- gestão por resultados

\author{
- gerenciamento de equipes \\ - relacionamento interpessoal \\ - desenvolvimento e valorização das pessoas \\ - preocupação com os interesses do grupo \\ - flexibilidade no estilo de gestão \\ - gerenciamento das emoções do grupo \\ - liderança \\ - motivação para trabalhar em equipe
}

O contexto da prática gerencial tem algumas especificidades inerentes ao ambiente externo da organização e outras vinculadas ao ambiente interno. Diante do que foi revelado na análise compreensiva interpretativa dos relatos dos gerentes acerca do contexto da prática gerencial, os resultados sugerem que o Banco do Brasil estabeleceu uma orientação estratégica que desencadeou várias transformações no contexto da prática gerencial. Daft (2003) considera que existem várias formas de as organizações lidarem com a competição. A busca da excelência, para o autor, envolve quatro fatores: orientação estratégica, alta administração, projeto organizacional e cultura organizacional.

No que se refere à orientação estratégica, a proximidade com o cliente, a busca de respostas rápidas diante de problemas e oportunidades, o foco e as metas empresariais estão presentes no contexto da prática gerencial. O processo de transformação ocorrido no Banco do Brasil parece ter trazido, com base na análise do que foi relatado pelos gerentes, implicações na visão das lideranças e uma preocupação com a institucionalização de valores básicos. No que se refere ao projeto organizacional, a reestruturação da empresa em pilares negociais segmentou o campo de atuação das agências, o que demandou uma estrutura mais ágil e descentralizada para atender às especificidades de cada campo de atuação.

De acordo com Salinas et al. (1998), o ajuste ocorrido no Banco do Brasil abrangeu uma reestruturação da direção geral e órgãos regionais, além do redimensionamento do quadro de pessoas e implantação de gerências regionais, a descentralização do processo decisório e a adoção de um modelo de administração colegiada. Contextualizando as considerações de Salinas et al. (1998) para o momento em que esta pesquisa foi realizada, fica evidente a consolidação desses ajustes, sobretudo daqueles que incidem diretamente na prática gerencial.

Uma análise dos relatos dos gerentes indica a existência de um relacionamento pautado pelo compartilhamento de informações, pela produtividade por meio das pessoas e pela preocupação com a gestão por resultados. Todo o processo de mudança ocorrido no contexto da organização levou os gerentes a repensar a sua forma de atuação no banco, provocando um processo de adaptação e aprendizado. 
A caracterização do contexto, a identificação de fatores determinantes na prática gerencial, os significados da família e suas bases de relações são fundamentais para a compreensão dos conflitos entre a prática gerencial e as relações em família.

No estudo realizado com gerentes emergiu um conceito de conflito na relação trabalho e família um pouco diferente do proposto por autores como Greenhauss e Beutell (1985), Carlson e Kacmar (2000) e Wilson et al. (2007). Esses autores o definem como um tipo de conflito de papéis em que as demandas de um domínio (trabalho ou família) são mutuamente incompatíveis com as demandas do outro domínio (família ou trabalho). No estudo realizado com gerentes, a palavra trabalho foi substituída por prática gerencial e a palavra família por relações em família. Tomando como base os resultados da pesquisa e a análise realizada, o conflito entre a prática gerencial e as relações em família está vinculado ao tempo dedicado ao exercício de papéis no trabalho e na família, à incompatibilidade de interesses e às divergências de percepção e de visão entre os agentes envolvidos.

Enquanto os conceitos propostos na literatura indicam o conflito na relação trabalho e família predominantemente como de papéis, a pesquisa realizada com os gerentes em uma agência do Banco do Brasil revelou que esses conflitos podem ser de papéis, de interesses e também de percepção (P. R. Motta, 1991). Morgan (1996) afirma que a origem dos conflitos está na divergência de interesses, mas também indica que eles surgem nos papéis e nas atitudes das pessoas. Follet (1997) também considera os conflitos decorrentes da diferença de opiniões e de interesses. Tjosvold (1996) indica a existência de uma visão predominante que define o conflito como interesses opostos.

O relato de conflitos entre a prática gerencial e as relações em família revelou, a partir da análise compreensiva interpretativa dos dados, alguns significados que ajudaram a compreender melhor o fenômeno, uma vez que os relatos das experiências dos gerentes expressaram fatores que geram conflito na prática gerencial e na família, e as suas conseqüências. Também indicam as repercussões da qualificação profissional e da prática gerencial nos conflitos familiares e os reflexos dos conflitos na família no seu desempenho no trabalho. Os gerentes reconheceram o diálogo como um fator que minimiza os conflitos entre a prática gerencial e as relações em família e expressaram atitudes para evitar o surgimento de conflitos nesta relação.

A Tabela 3 ilustra os fatores que desencadearam o surgimento de conflitos entre a prática gerencial e as relações em família, assim como as atitudes dos gerentes visando minimizar a incidência de conflitos nessa relação.

Tabela 3

O Conflito na Prática Gerencial e nas Relações em Família

\section{CATEGORIA}

Fatores que geram conflito na prática gerencial

Fatores que geram conflito nas relações em família

Atitudes para minimizar o conflito entre a prática gerencial e as relações em família

\section{SIGNIFICADOS}

Diferenças de percepção e de visão. Incompatibilidade de interesses. Falta de clareza no planejamento de suas atividades. Aumento da complexidade dos papéis gerenciais. Transformações ocorridas no Banco. Busca da qualificação. Possibilidade de ascensão na carreira.

Incapacidade de dialogar. Dificuldades na comunicação. Diferenças de percepção. Divergências entre os cônjuges.

Diálogo. Realização de atividades físicas, de lazer e a reflexão para manter a calma. Segmentação dos espaços sociais. 
A análise compreensiva interpretativa dos discursos dos gerentes indica a existência de fatores que geram conflito no trabalho e que ocorrem em virtude da divergência de percepções, visões e interesses na relação entre grupos, como também de mudanças no contexto da organização em que os gerentes atuam. Os conflitos decorrem das diferenças individuais (Quinn et al., 2003), mas também surgem a partir de transformações organizacionais. A incapacidade de planejar as atividades e o aumento da complexidade da prática gerencial também motivaram o surgimento de conflitos no trabalho dos gerentes.

Um conflito vivenciado no espaço da prática gerencial só passa a ter implicações para as relações em família, quando os gerentes necessitam despender mais tempo de dedicação ao trabalho e para atividades ligadas à aprendizagem, visando à qualificação necessária para se adequarem às mudanças organizacionais. Nos estudos de Pleck, Staines e Lang (1980), Greenhauss e Beutell (1985) e Carlson et al. (1995), o tempo dedicado ao trabalho foi indicado como um fator gerador de conflito na família. A dedicação de tempo para a prática gerencial decorre dos níveis de responsabilidade e de autoridade inerentes ao cargo, como também da necessidade de investimento em desenvolvimento profissional. Os resultados do estudo realizado por Pittman (1994) reforçam a existência de uma relação entre o tempo dedicado ao trabalho e a qualidade dos relacionamentos conjugais. Já o estudo realizado por Scanfone, Carvalho e Tanure (2007) avaliou como executivos de grandes empresas brasileiras distribuíam os seus tempos de trabalho e de não-trabalho e o impacto disto em suas vidas e revelou que os executivos têm a consciência de que a vida profissional consome a maior parte de seu tempo, e quase $80 \%$ deles estão insatisfeitos com a distribuição de tempo e energia entre o tempo dedicado ao trabalho e o tempo dedicado às dimensões do não-trabalho.

Existe a preocupação, por parte dos gerentes, em refletirem sobre as consequiências da ascensão profissional na vida em família, pois isso leva ao surgimento de um conflito de interesses: pessoais, profissionais e familiares. Os interesses, na percepção de Morgan (1996), estão ligados a objetivos, valores, desejos e expectativas, que levam as pessoas a adotarem determinados padrões de comportamento. Carlson e Kacmar (2000) consideram que os valores das pessoas, em relação aos papéis que realizam em cada domínio (família/trabalho), têm significativas implicações na vivência de conflitos.

Na prática gerencial, os fatores que levaram ao surgimento do conflito são decorrentes do contexto vivenciado pelos gerentes, o que suscita algumas conclusões. A primeira delas é que os conflitos na prática gerencial não podem ser analisados isoladamente. No quadro, por exemplo, fica evidente que na prática gerencial a incidência de conflitos está associada a fatores individuais, grupais e organizacionais. Outro aspecto a ser considerado envolve a busca da qualificação como fonte de conflito nas relações em família. A necessidade de qualificação profissional é um pré-requisito para a atuação de gerentes nas organizações em função do aumento da complexidade do contexto da prática gerencial. Na verdade, a busca da qualificação é um fator que gera conflito porque reduz o tempo de dedicação à família.

Já os conflitos nas relações em família estão associados à comunicação e ao relacionamento. A divergência entre os cônjuges está relacionada aos interesses pessoais, às diferenças de percepção e de pensamento. A existência de um distanciamento entre os membros da família, a falta de diálogo, as divergências de percepção e de valores na criação dos filhos, são geradores de conflitos. A falta de diálogo e a divergência na maneira como as pessoas interpretam o discurso reforçam a importância da comunicação na família, visando manter uma relação mais harmoniosa. As divergências entre os cônjuges estão intimamente relacionadas com a atitude impositiva de um dos membros da família em relação ao outro.

O diálogo, por exemplo, assume papel determinante nas relações em família, porquanto, além de ser uma base dessas relações, atua na minimização de conflitos e também na busca do seu equilíbrio. A partir dos resultados da pesquisa, o diálogo pode ser percebido como troca de idéias, de forma franca e aberta, uma relação de confiança recíproca. Na prática gerencial, o diálogo está associado a uma discussão que envolve vários pontos de vista e o estabelecimento de condições para uma decisão compartilhada. Nas relações em família, ele está associado à interação dos cônjuges, e deve auxiliar na 
reflexão dos problemas em busca de consenso, na adoção de posicionamento para alcançar um objetivo comum.

O diálogo estimula um relacionamento franco e aberto e cria uma relação de confiança, contribuindo para evitar a interferência de conflitos entre a prática gerencial e as relações em família. O bom relacionamento e maturidade são fatores essenciais para que o diálogo minimize a incidência de conflitos entre a prática gerencial e as relações em família.

No relacionamento em família, o diálogo com os filhos também contribuiu para evitar o surgimento de conflitos. O diálogo melhora as relações familiares (Cerveny, 2004), pois ajuda a promover uma relação de confiança recíproca (Farias, 2004). O estabelecimento do diálogo no ambiente profissional, envolvendo os conflitos decorrentes das relações em família, também pode indicar uma forma de reduzir a sua interferência no comportamento do gerente, reduzindo as suas implicações no desempenho profissional.

Além do diálogo, os gerentes expressaram outras atitudes para minimizar os conflitos entre a prática gerencial e as relações em família. Uma dessas atitudes envolve o desenvolvimento de atividades físicas e de lazer, além da reflexão como forma de lidar melhor com as possíveis interferências de conflito da prática gerencial na família. Outra alternativa é a criação de mecanismos para segmentar as relações entre os diversos espaços sociais.

O objetivo da segmentação é estabelecer uma fronteira física e psicológica. A noção de fronteira do sistema, proposta por Katz e Kahn (1987), pode ajudar a entender a segmentação dos espaços sociais (trabalho e família), uma vez que se refere "aos tipos de condições de barreira entre o sistema e seu meio, o que ocasiona graus de abertura ao sistema" (p. 79). Palavras como linha de demarcação, barreira, separação são citadas para caracterizar a fronteira. Pensar na criação de uma fronteira física entre o espaço social da família e do trabalho é fácil. O difícil é estabelecer a psicológica.

Um gerente afirma que cria uma fronteira psicológica, a fim de evitar que os conflitos do trabalho interfiram na família, mas não cria uma fronteira para evitar a interferência dos conflitos da prática gerencial nas relações em família. Nesse caso específico, a fronteira é unidireiconal. Na experiência de outro gerente, a fronteira psicológica envolve um processo de conexão mental. Ao ir para o trabalho, existe a conexão com esse espaço social. Ao sair do trabalho, a conexão para a vida familiar o leva a pensar os problemas e as atividades da prática gerencial a serem desenvolvidas.

Os gerentes apontaram atitudes que trazem contribuições para minimizar os conflitos. Uma delas ressalta a tentativa de evitar o transbordamento emocional negativo da prática gerencial para a família, e a outra sugere a segmentação dessa relação, por meio da criação de uma fronteira física e psicológica (Hall \& Richter, 1988), para evitar que o conflito familiar interfira na prática gerencial.

A segmentação trata o trabalho e a família como esferas separadas da vida. É um esforço consciente para delinear uma fronteira entre esses dois espaços sociais (Lambert, 1990; Smyrnios et al., 2003). Essa separação é intencional, quando envolve pensamentos, sentimentos e comportamentos adotados ao exercer um papel visando não afetar ao desempenho de outro papel (Lambert, 1990).

Esse processo não é fácil, pois os próprios gerentes não conseguem evitar a influência dos conflitos na prática gerencial, nas relações em família e também em si próprios. Na Tabela 4, são apresentados os significados dessas implicações. 
Tabela 4

Implicações dos Conflitos Vivenciados pelos Gerentes

\section{CATEGORIA}

Implicações dos conflitos experienciados na prática gerencial e nas relações em família nos gerentes

\section{SIGNIFICADOS}

Reações emocionais (magoa, irritação, angústia). Cansaço físico. Problemas de saúde (estresse, gastrite, insônia). Relações afetivas (discussões, atitudes inadequadas).

Redução do tempo dedicado à família. Privação do convívio familiar. Reclamações, cobranças e pressões da família. Sentimento de insegurança, de perda por parte da família. Divergências entre os cônjuges.

Dificuldade para a realização do trabalho. Mudança de humor. Falta de disposição. Preocupação. Dificuldade de concentração. Redução no desempenho.

Implicações dos conflitos familiares na prática gerencial

Implicações da qualificação profissional e da prática gerencial nos conflitos familiares

A percepção dos gerentes é de que os conflitos nas relações em família os afetam emocionalmente e isso se refletiu em seu desempenho (Carlson et al., 1995; Smyrnios et al., 2003; Wilson et al., 2007) na prática gerencial, pois estes levam a mudança de humor, a dificuldade de concentração, a preocupações e dificuldades na realização de atividades, uma vez que seus pensamentos se voltam para a situação que gerou o conflito no ambiente familiar.

Os conflitos decorrentes da prática gerencial também tiveram repercussões nas relações em família dos gerentes. Para eles, tanto os conflitos familiares quanto os conflitos experienciados na prática gerencial trouxeram consequiências emocionais e físicas. Nos resultados dos estudos realizados por Smyrnios et al. (2003) e Marchese et al. (2002), as conseqüências emocionais e físicas também foram indicadas como decorrentes dos conflitos na relação trabalho e família.

Pleck et al. (1980) ressaltam que, ao demandar alta carga física ou mental, o trabalho pode gerar fadiga e irritabilidade, causando problemas na família. Greenhauss e Beutell (1985) e Smyrnios et al. (2003) também destacaram a existência de evidências de que estressores no trabalho produzem sintomas de tensão, como ansiedade, fadiga, depressão, apatia e irritabilidade. No caso dos gerentes pesquisados, a pressão e o estresse do trabalho os deixaram cansados, exaustos, irritados. O tempo dedicado em um papel particular também pode produzir sintomas de tensão (Greenhauss \& Beutell, 1985).

Tanure, Carvalho e Motta (2007) realizaram um estudo com 965 executivos de grandes empresas brasileiras sobre o estresse, com o objetivo de identificar as possíveis correlações entre o padrão de comportamento (tipo A e B) e o nível de estresse. Os resultados da pesquisa indicam que os executivos com características do tipo A são os mais suscetíveis ao estresse, por serem mais competitivos, apressados e agressivos; os que gastam mais tempo com a vida profissional e também são os mais infelizes em relação à vida privada. Os principais sintomas de estresse dos executivos pesquisados envolvem a irritabilidade fácil, os ímpetos de raiva e a ansiedade. O estudo revelou a necessidade de conscientizar os executivos sobre suas atitudes em relação à vida profissional e particular, na busca de maior equilíbrio entre o trabalho e vida pessoal. Já no estudo realizado com 251 gerentes de lojas de Shopping Centers, Silva e Lima (2007) também constataram que 50,6 \% afirmam que o estresse causa reações físicas e emocionais, tais como impaciência, insônia, cansaço físico e mental, falta de disposição, dores musculares e irritabilidade. 
A análise das situações de conflito que os gerentes vivenciaram sugere, fortemente, a existência de um transbordamento ou sobrecarga emocional (Bartolomé \& Evans, 1980; Evans, 1996; Smyrnios et al., 2003). No caso dos gerentes pesquisados, o transbordamento ou sobrecarga emocional envolve pensamentos ou sentimentos associados à vivência de um conflito em uma dimensão (prática gerencial/relações em família) que repercute na outra (relações em família/prática gerencial). Lambert (1990) destaca que o transbordamento emocional pode ser negativo ou positivo. Na vivência de conflitos, na pesquisa realizada, esse transbordamento emocional é negativo, pois traz implicações para a prática gerencial. Ele seria positivo, se o gerente desenvolvesse, por exemplo, a habilidade para tomar decisões e usasse essa habilidade para lidar com seus filhos (Lambert, 1990).

Os resultados também ratificam a existência de uma bidirecionalidade dos conflitos entre a prática gerencial e a as relações em família (Marchese et al., 2002). Wilson, Polzer-Debruyne, Chen e Fernandes (2007) destacam que estudos envolvendo o equilíbrio na relação trabalho e vida pessoal revelam que o conflito em casa, na família, provoca atitudes negativas relacionadas ao trabalho, incluindo a redução da satisfação no trabalho, atrasos, absenteísmo, doenças, turnover e redução nos níveis de desempenho.

Quental e Wetzel (2002) reforçam essa percepção, ao indicarem que a interferência excessiva do trabalho na família pode levar ao surgimento de problemas de relacionamento com o cônjuge e isso tem implicações na qualidade da vida em família. O inverso também é apontado pelas autoras como prejudicial, na medida em que a interferência da família no trabalho pode trazer prejuízos à carreira, reduzindo a satisfação com a vida profissional. Na pesquisa realizada com gerentes do Banco do Brasil, a redução da satisfação não foi evidenciada. Todos demonstraram estar satisfeitos com a carreira escolhida.

Os dados revelados neste estudo indicam que os conflitos experimentados na prática gerencial trouxeram repercussões para as relações em família, quando demandaram um tempo maior de dedicação ao banco e à qualificação profissional. A necessidade de se dedicar mais ao trabalho e as pressões sofridas na organização trouxeram implicações ao convívio e ao distanciamento da família. Os conflitos emergiram em função das reclamações e das pressões da família, além do sentimento de perda e da insegurança causados por não participar do ambiente familiar, que os afetaram emocionalmente. Evans (1996) aponta as pressões do parceiro e da família como um indicador de que as pessoas estão insatisfeitas com o estilo de vida que levam. Acredita-se que a cobrança é um dos fatores que leva à insatisfação das pessoas, mas ela é natural na medida em que tanto a organização quanto os membros da família cobram um maior tempo de dedicação e isso leva um gerente ou qualquer pessoa a ter que fazer escolhas, estabelecer prioridades.

\section{CONSIDERAÇÕES FINAIS}

Este artigo procurou abordar o tema conflito na relação trabalho e família, a partir de uma perspectiva complexa e multidimensional. Compatibilizar os interesses associados ao cargo, à carreira e à vida fora da organização se tornou um processo mais difícil e muitos gerentes vivem um grande paradoxo: apesar das organizações destacarem a importância das dimensões subjetivas na prática gerencial, conscientizando-se de que o gerente tem a liberdade de expor o que pensa e de refletir e de questionar as ações organizacionais, os padrões de controle associados a um elevado nível de produtividade fazem com que o gerente valorize cada vez mais a dimensão trabalho e dedique a maior parte do seu tempo a questões relacionadas à atividade profissional. Sobra pouco tempo para a família, para os amigos e também para ele próprio. Ao dedicar mais energia e tempo a uma dimensão de suas vidas, os gerentes podem transformar-se em pessoas unidimensionais.

Tomando como base os resultados da pesquisa e a análise realizada, o conflito entre a prática gerencial e as relações em família está vinculado ao tempo dedicado ao exercício de papéis no trabalho 
e na família, à incompatibilidade de interesses e às divergências de percepção e de visão entre os agentes envolvidos.

A pesquisa revelou que os conflitos entre a prática gerencial e as relações em família trouxeram implicações para os gerentes. Esses resultados chamam a atenção, visto que as reações emocionais, o cansaço físico e os problemas de saúde prejudicam a vida do gerente e afetam a sua qualidade de vida dentro e fora da organização. Walton (1973) cita como critérios para a qualidade de vida, o "trabalho e o espaço total da vida" (p. 16), e destaca que as experiências individuais vivenciadas no trabalho podem ter efeitos positivos ou negativos em várias esferas da vida, como, por exemplo, as relações com a família. A sobrecarga de trabalho tem vários efeitos na vida dos trabalhadores, influenciando o exercício de papéis no ambiente familiar. A interferência de um papel no outro, de acordo com Quental e Wetzal (2002), pode "provocar sintomas de natureza psicológica, como ansiedade, fadiga e irritabilidade" (p. 2), dificultando a relação entre os dois papéis.

Tremblay (2004) relata estudos que comprovaram a dificuldade de pais conciliarem as obrigações profissionais e familiares em função da falta de tempo e isso os levou a se sentirem extremamente estressados e angustiados. A autora indica que, entre as várias soluções plausíveis, possíveis e aplicáveis, a flexibilidade do tempo para o trabalho é uma alternativa de conciliar o trabalho com a família e é a que apresenta maior interesse para empregadores e empregados.

Isso evidencia a necessidade de os profissionais que atuam em cargos de gerência, além dos responsáveis por formular as estratégias de gestão de pessoas, refletirem sobre as implicações do trabalho na vida familiar. Essa questão pode ser colocada no epicentro dos programas de formação e desenvolvimento gerencial, uma vez que os conflitos têm efeitos para os gerentes, suas famílias, bem como para a organização. Janasz e Behson (2007) reforçam essa constatação, ao indicarem que as organizações precisam repensar seus programas e políticas com o objetivo de auxiliar os trabalhadores e equilibrarem a relação trabalho e família. Moore (2007) associa o equilíbrio na relação trabalho e família a uma capacidade de equilibrar o seu comprometimento com os dois espaços sociais e que existe uma correlação positiva entre os programas voltados para a conciliação trabalho e vida pessoal e a lealdade com a organização. Silva e Rossetto (2007) reforçam que os gerentes buscam o equilíbrio na relação entre a prática gerencial e a vida em família como uma tentativa de compatibilizar os interesses pessoais, profissionais e familiares. "Da mesma forma que o conflito surge quando existem divergências de interesses, a busca do equilíbrio se dá quando esses interesses são conciliados" (p. 14).

Lenaghan, Buda e Eisner (2007) consideram que o conflito na relação trabalho e família é uma questão que não pode ser ignorada e sugerem que os profissionais de recursos humanos precisam explorar oportunidades de aprendizagem, assim como criar um ambiente que reconheça o valor da auto-reflexão. Destacam, ainda, a importância da cultura organizacional no apoio e no encorajamento dos empregados na busca do autoconhecimento, por meio de treinamento e exercícios. A alocação de recursos pode ajudar os empregados a aprenderem a ser resilientes e também desenvolverem a inteligência emocional, apontada pelos autores como uma variável protetora para o bem-estar dos sujeitos que estão experienciando um conflito na relação trabalho e família.

Algumas ações empreendidas para minimizar os conflitos na relação trabalho e família envolvem flexibilidade nos horários e na jornada de trabalho, programas de apoio psicológico, incentivo ao diálogo do tema nas relações interpessoais, planejamento e organização da agenda de trabalho, entre outros.

A vivência de conflitos familiares repercute no exercício da prática gerencial que coaduna na redução do nível de desempenho. Isso ocorre porque os gerentes não conseguem "desligar-se" dos conflitos familiares, quando estão no ambiente de trabalho, o que acaba afetando a concentração e disposição para o trabalho. É uma sensação de mal-estar na família que repercute no desempenho das atividades na prática gerencial (Silva \& Rossetto, 2007).

Esses resultados indicam a necessidade de as organizações se conscientizarem de que o desempenho dos gerentes é extremamente afetado por conflitos familiares, o que se reflete no próprio desempenho 
da organização. F. C. P Motta e Vasconcellos (2002) consideram que os conflitos de papéis afetam a satisfação no trabalho e tem um custo elevado, na medida em que influenciam as dimensões emocional e interpessoal. Outra conclusão do estudo é que os conflitos familiares também representam um custo para a organização.

Esse novo cenário que se delineia na vida de pessoas que atuam em cargos gerenciais, suscita um processo de transformação decorrente das mudanças no ambiente empresarial e nas relações em família. No caso dos gerentes pesquisados, todas as suas esposas exercem uma atividade profissional e as responsabilidades na educação dos filhos e das atividades domésticas, em sua maioria, precisam ser compartilhadas. Os profissionais e as organizações precisam estar atentos para a necessidade de avaliar o impacto que as transformações organizacionais, sociais e culturais trazem para a vida das pessoas, uma vez que estudos revelam que os conflitos na relação trabalho e família influenciam os níveis de sasfação e de comprometimento no trabalho, provocam estresse, burnout, turnover, absenteísmo, insatisfação na vida conjugal, que trazem impactos no desempenho profissional e também para a qualidade de vida dos profissionais (Burchielli, Bartram, \& Thanacoody, 2008; Janasz $\&$ Behson, 2007; Wilson, Polzer-Debruyne, Chen, \& Fernandes, 2007).

Vale ressaltar que o estudo apresenta limitações. A primeira delas envolve a abordagem utilizada. Os resultados não podem ser generalizados, mas espera-se que eles contribuam para levar os profissionais que atuam em cargos gerenciais a um processo de reflexão, além de despertar o interesse de pesquisadores na realização de estudos complementares. Outro ponto a ser considerado é que a pesquisa foi realizada com homens casados, com uma carreira estabilizada e que atuam em um contexto específico. Portanto, os resultados se referem às experiências dessas pessoas, articuladas com a literatura e interpretadas pelo pesquisador.

Estudos adicionais que envolvem o tema devem considerar os vínculos entre o gênero, a personalidade, o contexto, o tipo de trabalho, o estágio da carreira (Hall \& Richter, 1988; Kossek et al., 1999). Também é preciso considerar a diversidade cultural e também as áreas e os níveis de atuação dos gerentes nas organizações e também desenvolver estudos que envolvem profissionais que não atuam em cargos gerenciais (Moore, 2007). Abordar o tema numa perspectiva complexa e multidimensional é uma forma de reconhecer a existência de conexões espaciotemporais e comportamentais (Clark, 2000) e essa constatação pode auxiliar a compreender a experiência vivida de gerentes de forma singular e multifacetada. Espera-se que o tema amplie o foco de análise do conflito e auxilie na compreensão da teoria e da prática organizacional.

\section{Artigo recebido em 20.09.2007. Aprovado em 28.10.2008.}

\section{NOTA}

\footnotetext{
1 Para Fini (1994, p. 28), "os dados são, pois, as situações vividas pelos sujeitos que são tematizadas por eles, conscientemente na descrição que fazem. Ao descrevê-las, espera-se que os sujeitos simplesmente relatem, de modo preciso, o que ocorre com eles ao viver suas experiências".
}

\section{REFERÊNCIAS BIBLIOGRÁFICAS}

Ahmad, M. S. S. (2003). Work-family conflict: a survey of singaporean workers. Singapore Management Review, 25(1), 35-51.

Antunes, R. (2000). Adeus ao trabalho? Ensaio sobre as metamorfoses e a centralidade do mundo do trabalho (7a ed.). São Paulo: Cortez. 
Barnard, C. I. (1971). As funções do executivo. São Paulo: Atlas.

Barrit, L., Beekman, T., Bleeker, H., \& Mulderij, K. (2000). Analyzing phenomenological descriptions. Phenomenology + Pedagogy, 2(1), 1-17.

Bartolomé, F., \& Evans, P. A. L. (1980). Must success cost so much? Harvard Business Review, 58(2), 137-148.

Bicudo, M. A. V. (2000). Fenomenologia: confrontos e avanços. São Paulo: Cortez.

Bicudo, M. A. V., \& Esposito, V. H. C. (Orgs.). (1994). A pesquisa qualitativa em educação: um enfoque fenomenológico. Piracicaba: Unimep.

Burchielli, R., Bartram, T., \& Thanacoody, R. (2008). Work-family or greedy organizations? Relations Industrielles, 63(1), 108-162.

Burrell, G., \& Morgan, G. (1979). Sociological paradigms and organizational analysis. Heinemann: London.

Carlson, D. S., \& Kacmar, K. M. (2000). Work-Family conflict in the organization: do life role values make a difference? Journal of Management, 26(5), 1031-1054.

Carlson, D. S., Kacmar, K. M., \& Stepina, L. P. (1995). An examination of two aspects of workfamily conflict: time and identity. Women in Management Review, 10(2), 17-25.

Carponi, P. J. (1997). Work/life balance: you can't get there from here. The Journal of Applied Behavioral Science, 33(1), 46-56.

Cerveny, C. M. O. (2004). Família e comunicação. In C. M. O. Cerveny (Org.). Família e comunicação, divórcio, mudança, resiliência, deficiência, lei, bioética, doença, religião e drogadição (pp. 13-24). São Paulo: Casa do Psicólogo.

Chanlat, J. F. (Coord). (1992). O indivíduo na organização: dimensões esquecidas. São Paulo: Atlas.

Clark, S. C. (2000). Work/Family border: a new theory of work/family balance. Human Relations, 56(6), 747-770.

Daft, R. L. (2003). Organizações: teoria e projetos. São Paulo: Thomson Learning.

Debord, K., Canu, R. F., \& Kerpelman, J. (2000). Understanding a work-family fit for single parents moving from welfare to work. Social Work, 45(4), 313-324.

Desiderio, F. ( 1983). Convívio: análise dos aspectos relacionais humanos. Petrópolis: Vozes.

Dewey, J. (1979). Democracia e educação: introdução à filosofia da educação (4a ed.). São Paulo: Nacional.

Escrivão, E., Filho (1995). A natureza do trabalho do executivo: uma investigação sobre as atividades racionalizadoras do responsável pelo processo produtivo em empresas de médio porte. Tese de doutorado, Universidade Federal de Santa Catarina, Florianópolis, SC, Brasil.

Evans, P. (1996). Carreira, sucesso e qualidade de vida. Revista de Administração de Empresas, 36(3), 14-23.

Farias, C. C. (2004). A família da pós-modernidade: em busca da dignidade perdida da pessoa humana. Revista de Direito Privado, 5(19), 56-68.

Fayol, H. (1994). Administração industrial e geral (10a ed.). São Paulo: Atlas. 
Follet, M. P. (1997). Profeta do gerenciamento. Rio de Janeiro: Qualitymark.

Fu, C. K., \& Shaffer, M. A. (2001). The tug of work and family: direct and indirect domain-specific determinants of work-family conflict. Personnel Review, 30(5), 502-522.

Greenhaus, J. H., \& Beutell, N. J. (1985). Sources of conflict between work and family roles. Academy of Management Review, 10(1), 76-88.

Haddock, S. A., Zimmerman, T. S., Ziemba, S. J., \& Curent, L. R. (2001). Ten adaptive strategies for family and work balance: advice from successful families. Journal of Marital and Family Therapy, 27(4), 445-458.

Hall, D. T., \& Richter, J. (1988). Balancing work life and home life: what can organizations do to help? The Academy Management Executive, 2(3), 213-223.

Harvey, D. (2000). Condição pós-moderna (9a ed.). São Paulo: Edições Loyola.

Heloani, R. (1994). Organização do trabalho e administração: uma abordagem multidisciplinar. São Paulo: Cortez.

Hill, L. (1993). Novos gerentes: assumindo uma nova identidade. São Paulo: Makron Books.

Janasz, S. C., \& Behson, S. J. (2007). Cognitive capacity for processing work-family conflict: an initial examination. Career Development International, 12(4), 397-411.

Katz, D., \& Kahn, R. L. (1987). Psicologia social das organizações (3a ed.). São Paulo: Atlas.

Kerslake, P. (2002). Do the right thing: the work/life balance pay-back. New Zealand Management, 49(5), 28-31.

Kiecolt, K. J. (2003). Satisfation with work and family life: no evidence of a cultural reversal. Journal of Marriage and Family, 65(1), 23-35.

Kossek, E. E., Noe, R. A., \& Demarr, B. J. (1999). Work-family role synthesis: individual and organizational determinants. The International Journal of Conflict Management, 10(2), 102-130.

Kotter, P. J. (1982). What effective general managers really do? Harvard Business Review, 60(6), 156167.

Lambert, S. J. (1990). Processes linking work and family: a critical review and research agenda. Human Relations, 43(3), 239-257.

Le Boterf, G. (2003). Desenvolvendo a competência dos profissionais (3a ed.). Porto Alegre: Bookman.

Lenaghan, J. A., Buda, R., \& Eisner, A. B. (2007). An examination of the role of emotional intelligence in work and family conflict. Journal of Management Issues, 19(1), 76-94.

Lôbo, P. L. N. (2004). A repersonalização das relações de família. Revista de Direito Privado, 19(5), 242-259.

Manen, M. van (1990). Researching lived experience: human science for an action sensitive pedagogy. London, Ontario, Canadá: University of Western Ontario.

Marchese, M. C., Basshan, G., \& Ryan, J. (2002). Work-family conflict: a virtue ethics analysis. Journal of Business Ethics, 40(2), 145-154.

Maximiano, A. C. A. (2002). Teoria geral da administração: da escola científica à competitividade na economia globalizada (2a ed.). São Paulo: Atlas. 
Merriam, S. B. (1998). Qualitative research and case study applications in education. San Francisco, CA: Jossey-Bass.

Mintzberg, H. (1973). The nature of managerial work. New York, NY: HarperCollins Publishers.

Mintzberg, H. (1990).The manager's job: folklore and fact. Haward Business Review, 6(8), 163 176.

Moore, F. (2007). Work-life balance: contrasting managers and workers in an MNC. Employee Relations, 29(4), 385-399.

Morgan, G. (1980). Paradigm, metaphors, and puzzle solving in organization theory. Administrative Science Quaterly, 25(4), 605-622.

Morgan, G. (1996). Imagens da organização. São Paulo: Atlas.

Morgan, G., \& Smircich, L. (1980). The case for qualitative research. Academy of Management Review, 5(4), 491-500.

Morin, E., \& Le Moigne, J. (2000). A inteligência da complexidade (2a ed.). São Paulo: Petrópolis.

Moscovici, F. (2000). Renascença organizacional (8a ed.). Rio de Janeiro: José Olympio.

Motta, F. C. P., \& Vasconcelos, I. F. G. (2002). Teoria geral da administração. São Paulo: Thomson.

Motta, P. R. (1991). Gestão contemporânea: a ciência e a arte de ser dirigente (2a ed.). Rio de Janeiro: Record.

Oliveira, N. (2001). Mudanças organizacionais e qualidade de vida no trabalho: um estudo comparativo-temporal em unidades do Banco do Brasil S.A. Dissertação de mestrado, Universidade Federal de Minas Gerais, Belo Horizonte, MG, Brasil.

Oliveira, N., \& Moraes, L. F. R. (1999, setembro). Clima organizacional: discussões metodológicas sobre a implantação de uma pesquisa no Banco do Brasil S/A. Anais do Encontro Nacional da Associação Nacional de Pós-Graduação e Pesquisa em Administração, Foz do Iguaçu, PR, Brasil, 23.

Parcel, T. L. (1999). Work and family in the 21st century. Work and Occupations, 26(2), 264-274.

Pittman, J. F. (1994). Work/Family fit as a mediator of work factors on marital tension: evidence from the interface of greedy institutions. Human Relations, 47(2), 183-209.

Pleck, J. H., Staines, G. L., \& Lang, L. (1980). Conflict between work and family life. Monthly Labor Review, 103(3), 29-32.

Quental, C., \& Wetzel, U. (2002, setembro). Equilíbrio trabalho-vida e empreendedorismo: a experiência das mulheres brasileiras. Anais do Encontro Nacional da Associação Nacional de Pós-Graduação e Pesquisa em Administração, Salvador, BA, Brasil, 26.

Quinn, R. E., Faerman, S. R., Thompson, M. P., \& McGrath, M. (2003). Competências gerenciais: princípios e aplicações. Rio de Janeiro: Elsevier.

Reimbold, M. F., \& Breillot, J. M. (1995). Gerer la competence dans l'entreprise. Paris: Editions L'Harmattan.

Rizzo, J. R., House, R. J., \& Lirtman, S. I. (1970). Role conflict and ambiguity in complex organizations. Administrative Science Quarterly, 15(2), 150-163. 
Robbins, S. P. (2002). Comportamento organizacional. São Paulo: Prentice Hall.

Rocha, A. S. C., \& Bastos, A. V. B. (1999, setembro). Comprometimento do empregado e contextos organizacionais em mudança: o caso do Banco do Brasil. Anais do Encontro Nacional da Associação Nacional de Pós-Graduação e Pesquisa em Administração, Foz do Iguaçu, PR, Brasil, 23.

Romagnoli, R. C. (1996). (Dês) conhecendo a família. Caderno de Psicologia, 6(8), 13-19.

Rondeau, A. (1996). A gestão dos conflitos nas organizações. In J. F. Chanlat (Coord.). O indivíduo na organização: dimensões esquecidas (Vol. 3). São Paulo: Atlas.

Salinas, J. L., Maçada, A. C. G., \& Ritter, M. E. (1998, setembro). Mudança radical em organizações complexas: o caso do Banco do Brasil. Anais do Encontro Nacional da Associação Nacional de Pós-Graduação e Pesquisa em Administração, Foz do Iguaçu, PR, Brasil 22.

Santos, E. K. A. (2004). A expressividade corporal do ser-mulher/mãe HIV positiva frente a privação do ato de amamentar: a compreensão do significado pela enfermeira à luz da teoria da expressão de Merleau-Ponty. Tese de doutorado, Universidade Federal de Santa Catarina, Florianópolis, SC, Brasil.

Scanfone, L., Carvalho, A., Neto, \& Tanure, B. (2007, setembro). Tempos de trabalho e de nãotrabalho: o difícil equilíbrio do alto executivo entre a carreira, as relações afetivas e o lazer. Anais do Encontro Nacional da Associação Nacional de Pós-Graduação e Pesquisa em Administração, Rio de Janeiro, RJ, Brasil, 31.

Seidman, I. (1997). Interviewing as qualitative research: a guide for researchers in education and the social sciences (2a ed.). New York: Teachers College Press.

Sennet, R. (2000). A corrosão do caráter: conseqüências pessoais do trabalho no novo capitalismo (4a ed.). São Paulo: Record.

Silva, A. B., \& Lima, N. M. V. (2007). Relação trabalho e família: percepção de gerentes dos shopping centers da cidade de natal/RN. In C. F. Ângelo, \& J. A. G. Silveira (Coords.). Varejo competitivo (Vol. 12, Cap. 10, pp. 272-296). São Paulo: Saint Paul.

Silva, A. B., \& Rebelo, L. M. B. (2003). A emergência do pensamento complexo nas organizações. Revista de Administração Pública, 37(4), 777-796.

Silva, A. B., \& Rossetto, C. R. (2007, junho). A busca do equilíbrio na relação trabalho e família: um estudo com gerentes do banco do Brasil. Anais do Encontro de Gestão de Pessoas e Relações de Trabalho, Natal, RN, Brasil, 1.

Smyrnios, K. X., Romano, C. A., Tanewski, G. A., Karofsky, R. M., Millen, R., \& Yilmaz, M, R. (2003). Work-family conflict: a study of american and australian family businesses. Family Business Review, 16(1), 35-51.

Stewart, R., \& Fondas, N. (1992). How managers can think strategically about their jobs. Journal of Management Development, 11(7), 10-17.

Tanure, B., Carvalho, A., Neto, \& Mota, C. M. (2007, junho). Muito estresse. In Satisfações e infelicidades: um retrato dos altos executivos. Anais do Encontro de Gestão de Pessoas e Relações de Trabalho, Natal, RN, Brasil, 1.

Thompson, J. A., \& Bunderson, J. S. (2001). Work-nonwork conflict and the phenomenology of time. Work and Ocupations, 28(1), 17-39. 
Tjosvold, D. (1996). Conflict management in a diverse world: a review essay of caplan's understanding disputes: the politics of argument. Human Relations, 49(9), 1203-1211.

Tonelli, M. J., \& Alcadipani, R. (2003, setembro). O trabalho dos gerentes. A mudança que não ocorreu. Anais do Encontro Nacional da Associação Nacional de Pós-Graduação e Pesquisa em Administração, Atibaia, SP, Brasil, 27.

Tremblay, D. (2004, setembro). Desafios da conciliação entre trabalho e família nas empresas canadenses: experiência sindical e gestão de recursos humanos. Anais do Encontro Nacional da Associação Nacional de Pós-Graduação e Pesquisa em Administração, Curitiba, PR, Brasil, 28.

Valcour, P. M. (2002). Managerial behavior in a multiplex role system. Human Relations, 55(10), 1163-1188.

Walton, R. E. (1973). Quality of working life: what is is? Sloan Management Review, 15(1), 11-21.

Wilson, M. G., Polzer-Debruyne, A., Chen, S., \& Fernandes, S. (2007). Shift work interventions for reduced work-family conflict. Employee Relations, 29(2), 162-177.

Zarifian, P. (2001). Objetivo competência. São Paulo: Atlas. 